\title{
Espectrogramas sonoros da guitarra, do baixo e da bateria
}

\author{
Galgano, G. D. ${ }^{1^{*}}$ \\ ${ }^{1}$ Departamento de Química e Física, Universidade Federal do Espírito Santo, Alegre, ES, Brasil.
}

*e-mail: giovanni.galgano@ufes.br

\begin{abstract}
Resumo
A formação musical guitarra, baixo e bateria, é uma das mais recorrentes na música popular por conta de sua grande versatilidade em um arranjo compacto. As relações entre essa combinação de instrumentos musicais e o desenvolvimento da física e de suas aplicações são discutidos ao longo deste trabalho. Fizemos uma análise acústica, explorando e discutindo os princípios físicos envolvidos na composição dos timbres. O som produzido por cada componente de cada instrumento foi registrado em formato digital e convertido em um espectrograma sonoro. Tal gráfico fornece uma representação do espectro de frequências de uma forma de onda em função do tempo, de onde é possível extrair parâmetros como a intensidade e duração individual dos modos normais de vibração dos elementos oscilantes. As discussões sobre Física Aplicada pautadas nesses instrumentos musicais são de interesse, tanto do ponto de vista do ensino de física e popularização da ciência e tecnologia, quanto do estudo e compreensão da música em termos de seus aspectos físicos e matemáticos.
\end{abstract}

Palavras chaves: acústica musical, organologia, espectrograma sonoro, música popular.

\begin{abstract}
The musical formation of guitar, bass and drums is one of the most recurrent in popular music due to its great versatility in a compact arrangement. The relationships between this combination of musical instruments and the development of physics and its applications are discussed throughout this work. We did an acoustic analysis, exploring and discussing the physical principles involved in the composition of the timbres. The sound produced by each component of each instrument was recorded in digital format and converted into a sound spectrogram. Such a graph provides a representation of the frequency spectrum of a waveform as a function of time, from which it is possible to extract parameters such as the intensity and individual duration of the normal modes of vibration of the oscillating elements. The discussions on Applied Physics based on these musical instruments are of interest, both from the point of view of teaching physics and popularizing science and technology, as well as the study and understanding of music in terms of its physical and mathematical aspects.
\end{abstract}

Keywords: musical acoustics, organology, sound spectrogram, popular music.

\section{Introdução}

No século $X X$ a sociedade passou por transformações profundas introduzidas por aplicações da física. A exemplo disso, temos a teoria clássica do eletromagnetismo, que aplicada a circuitos elétricos deu origem à eletrônica, ou a mecânica quântica, que aplicada à tecnologia de semicondutores possibilitou a grande difusão da informática. Na área da música, surgiram recursos como a gravação magnética e a amplificação eletrônica, que revolucionaram o fazer e o pensar da música. Novos gêneros, como o rock, o pop e a "música eletrônica" surgiram na segunda metade do século $X X$, como consequência direta dos avanços na eletrônica e telecomunicações. Desde o surgimento do rock nos Estados Unidos na década de 1950 com nomes como Chuck Berry, Bill Haley e Elvis Presley [1,2], o rock vem influenciando a música popular [3], sobretudo com a sua instrumentação essencial: a guitarra, o baixo e bateria. Para buscar entender a preferência por esses três instrumentos, vamos analisar a fundo as suas características sonoras individuais, do ponto de vista da acústica musical. Entretanto, antes de prosseguir, faremos uma breve contextualização histórica, para melhor entender como e por que esses três instrumentos foram combinados e assim permaneceram.

Vamos começar no final do século XIX, quando a teoria clássica do eletromagnetismo havia sido consolidada com as equações de Maxwell (1861-62), "triunfantemente corroborada pela demonstração de 
Hertz da existência das ondas eletromagnéticas em 1988" [5] e o elétron seria descoberto por J.J. Thomspon quase na virada do século em 1897. Nessa época, os Estados Unidos estavam em reconstrução após o período da Guerra Civil, que perdurou de 1861 a 1865 e terminou com os estados confederados do Sul derrotados e a escravidão abolida no país. Foi nesse período, nas lavouras de algodão da região do Delta do Rio Mississipi [6], que surgiu o estilo musical africano-americano conhecido como blues [79]. As canções eram acompanhadas por uma instrumentação mínima [10], com poucos elementos como violões, gaitas, e instrumentos de percussão, por vezes improvisados, como o cowbell, feito de um antigo sino de vaca que perdeu seu badalo, ou uma tábua de lavar roupas, como no retrato da figura 1, nas mãos de Washboard Sam. Apesar de relativamente simples, a instrumentação do blues antigo era suficiente para fornecer os elementos essenciais à música: harmonia, melodia, ritmo e contraponto.

Durante as primeiras décadas do século $X X$, o blues se popularizou e incorporou elementos das bandas marciais, como instrumentos de sopro, tambores e pratos, além de instrumentos clássicos como o piano, o violino e o contrabaixo. Dessa ramificação mais erudita do blues nasceu o jazz [11], cuja formação instrumental varia desde duos e trios, até grupos maiores, com os metais saxofone, trompete e trombone mais uma seção rítmica, com as cordas e a bateria, as chamadas bigbands. As bigbands foram responsáveis pela cena musical predominante nos EUA no período entre a Grande Depressão (1929) e o final da Segunda Guerra Mundial (1945), a chamada Era do Swing [12]. Esse arranjo, embora muito eficiente, podia atender apenas a um número limitado de ouvintes. Nem mesmo bigbands com uma ou duas dúzias de instrumentistas seriam capazes de atender à demanda de decibéis das multidões que vinham sendo nutridas desde os anos de 1930 pela indústria cultural e que eclodiram com a cultura de massa difundida no período pós Segunda Guerra Mundial e década de 1950. Foi apenas com o desenvolvimento da eletrônica e de suas aplicações em tecnologias de comunicação, tais como gravadores, alto-falantes, microfones, antenas de rádio e televisão, que a música passou por uma mudança de paradigma sem precedentes na história.

A amplificação elétrica permite ganho arbitrário do nível de pressão sonora de uma fonte, controlado pelo recém criado botão de volume, dependendo apenas da potência máxima do sistema utilizado [13]. Em especial o contrabaixo microfonado e mais adiante o baixo elétrico, ganharam um espaço renovado na mescla com os demais instrumentos, sendo possível compensar pela redução natural da percepção na faixa dos graves com o aumento do ganho do amplificador. Assim como no contrabaixo, um violão microfonado seria uma boa solução para preencher a harmonia e passagens solo (como é em muitos casos na música popular), porém a utilização do captador de indução tornou completamente dispensável a caixa acústica do violão, dando origem à guitarra elétrica de corpo sólido, que não foi apenas uma adaptação do violão. A guitarra elétrica se tornou um instrumento completamente novo, com características singulares, agregando sonoridades e técnicas originais, além de frequentemente contar com processamentos eletrônicos do sinal, através dos pedais de efeito. Já para a bateria, embora versões eletrônicas comerciais tenham surgido nos anos 1970 e estejam até hoje em desenvolvimento, ainda são instrumentos complexos e pouco acessíveis economicamente, portanto não tão frequentes em estúdios de gravação e shows, sendo a bateria acústica captada com microfones ainda a preferência da maioria dos bateristas.

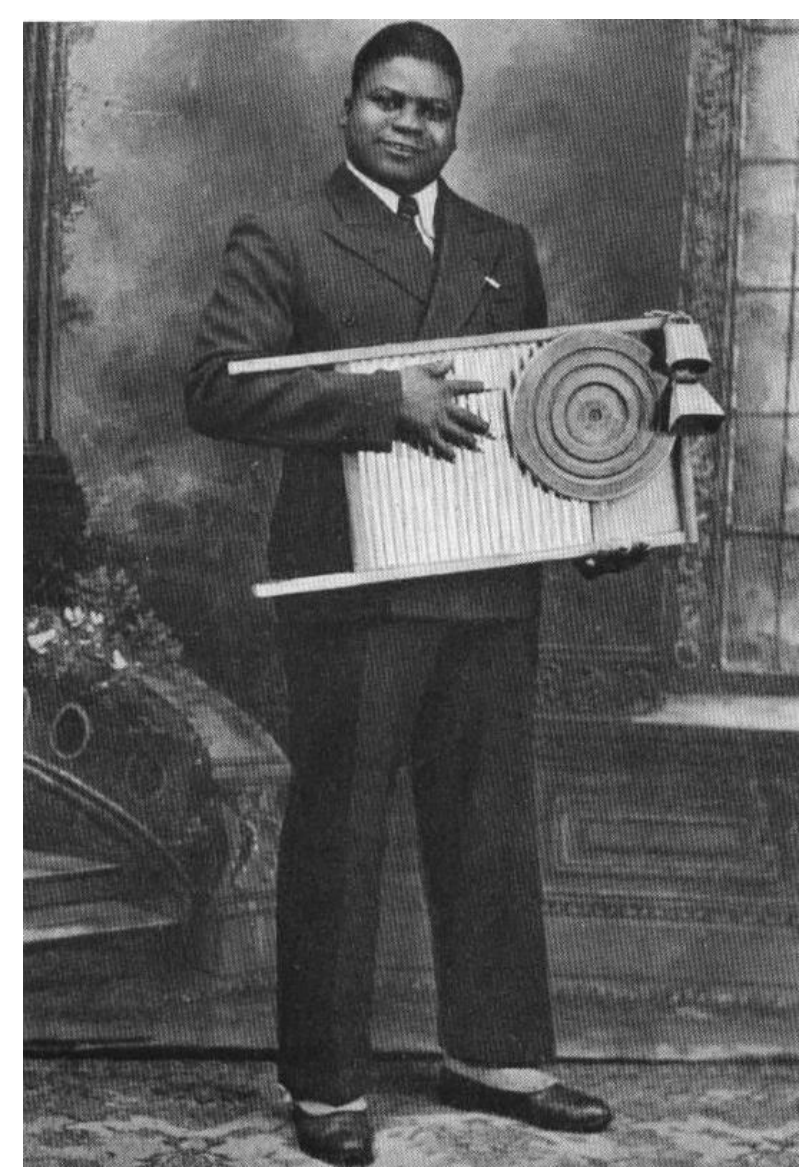

Figura 1: Washboard Sam em 1931 [10] segurando a tábua de lavar roupas, equipada com dois sinos de vaca e um prato de toca-discos.

\section{Metodologia}

Os registros em formato digital WAV foram feitos com uma interface de áudio TASCAM MINISTUDIO US-42, onde foram ligados diretamente a guitarra e o baixo, utilizando o ajuste de impedância adequado. Para a captação da bateria utilizamos um microfone do tipo dinâmico com sensibilidade e impedância especificados pelo fabricante de $-51,5 \mathrm{~dB}$ e $600 \Omega$, respectivamente e resposta de frequência de $70 \mathrm{~Hz}$ a $16 \mathrm{kHz}$. 


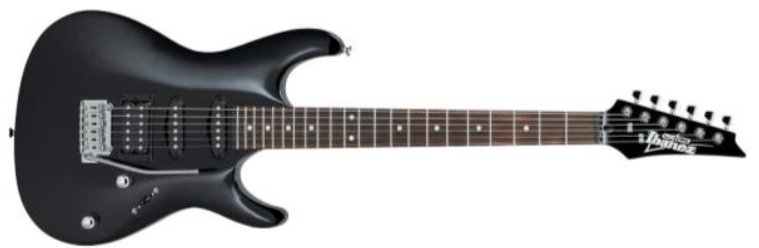

Figura 2: Ibanez GSA60.

A guitarra elétrica analisada foi uma lbanez GSA60 apresentada na Figura 2. Esse modelo possui o corpo feito em agathis, braço em bordo e escala em jacarandá. Na parte da mão da guitarra, as cordas são acomodadas em sulcos na pestana e enroladas em tarraxas com as quais é feito o controle da tensão, $\mathrm{T}$, de cada corda. Na outra extremidade, junto ao corpo da guitarra, as cordas são fixadas numa ponte tremolo sincronizada, onde o acionamento da alavanca causa uma igual redução na tensão de todas as cordas. O baixo gravado foi um lbanez GSR395, mostrado na figura 3. Com cinco cordas e comprimento de escala de $864 \mathrm{~mm}$ (34"), esse instrumento é capaz de atingir notas de frequências próximas ao limite inferior do espectro audível. Os captadores de indução são passivos, de bobina simples.

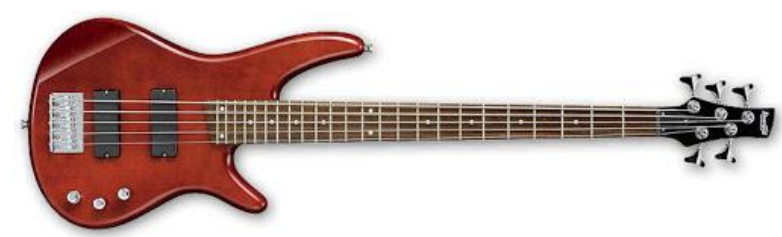

Figura 3: Baixo elétrico Ibanez GSR395.

Tabela 1: Parâmetros de afinação das cordas da guitarra e do baixo. Guitarra Baixo

\begin{tabular}{ccccc} 
Nota & $\mathbf{D}(\mathbf{m m})$ & $\mathbf{f}(\mathbf{H z})$ & $\mathbf{D}(\mathbf{m m})$ & $\mathbf{f}(\mathbf{H z})$ \\
\hline $\mathrm{Mi}$ & 0,23 & 329,60 & - & - \\
$\mathrm{Si}$ & 0,28 & 246,90 & - & - \\
$\mathrm{Sol}$ & 0,41 & 196,00 & 1,02 & 98,00 \\
$\mathrm{Ré}$ & 0,61 & 146,80 & 1,52 & 73,42 \\
Lá & 0,81 & 110,00 & 1,91 & 55,00 \\
$\mathrm{Mi}$ & 1,07 & 82,41 & 2,41 & 41,20 \\
$\mathrm{Si}$ & - & - & 3,18 & 30,87 \\
\hline
\end{tabular}

Tanto na guitarra quanto no baixo, o comprimento total da escala, L, dado pela distância entre os pontos de apoio das cordas na pestana e na ponte, pode ser ajustado em alguns milímetros na direção do braço, ou contrária, de forma que a afinação se mantenha correta (mas não justa [14]) ao longo de toda a escala. $O$ terceiro parâmetro que determina a frequência, $f$, de vibração do modo fundamental de vibração de uma corda é o diâmetro D, [15]. Na aproximação de uma corda cilíndrica, homogênea, de densidade volumétrica de massa $\rho$ e $L>>D$, tal frequência é dada por [16]

$$
f=(L D)^{-1}(T / \pi \rho)^{1 / 2}
$$

Na tabela 1 estão listados os diâmetros, D, das cordas instaladas na guitarra e no baixo.

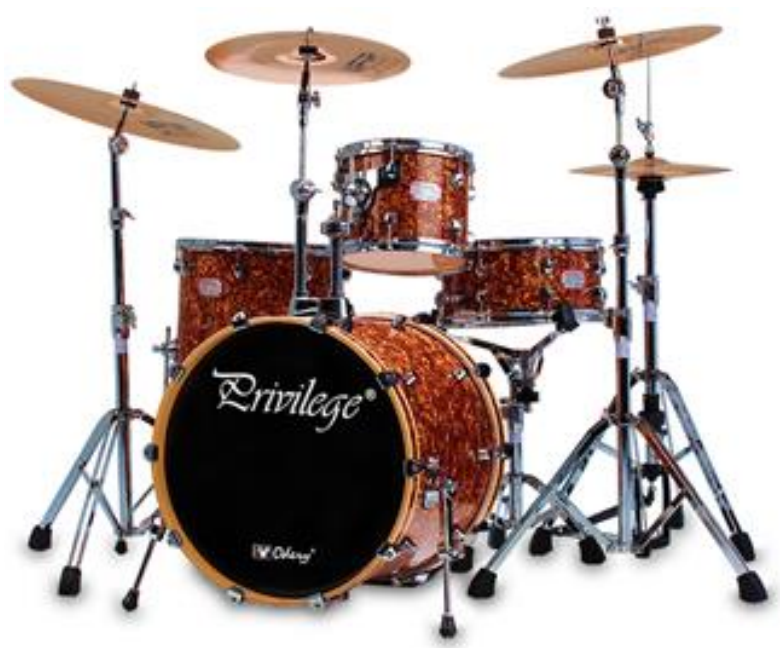

Figura 4: Bateria com tom tom, caixa, surdo e bumbo, pratos chimbal, ataques e condução.

A bateria, ilustrada na figura 4 , é composta por tambores de madeira Odery, série Privilege Jazz. Os pratos são Zeus, série Hybrid, feitos em liga de bronze B20. As medidas dos pratos e tambores estão relacionadas na tabela 2 . Com relação às peles, na caixa são necessárias duas peles, a superior, onde ocorre a percussão com as baquetas e a inferior, onde é instalada a esteira. Nos demais tambores, inclusive o bumbo, optamos por utilizar apenas uma pele, para simplificar o sistema. A tensão da pele foi uniformizada com ajuda do calibrador Tension Watch da marca Tama, que com uma agulha carregada com uma mola, fornece uma medida precisa da tensão relativa entre diferentes regiões da pele. O balanceamento da tensão em todos os pontos da pele é importante para evitar separação de modos, como discutido em [17].

\begin{tabular}{|c|c|c|c|c|c|}
\hline & \multirow[b]{2}{*}{ Peça } & \multicolumn{2}{|c|}{ diâmetro } & \multicolumn{2}{|c|}{ Altura } \\
\hline & & (pol.) & $(\mathrm{cm})$ & (pol.) & $(\mathrm{cm})$ \\
\hline \multirow{4}{*}{ 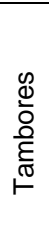 } & Caixa & 13 & 33,02 & 5,5 & 13,97 \\
\hline & Tom & 10 & 25,40 & 8 & 20,32 \\
\hline & Surdo & 14 & 35,56 & 13 & 33,02 \\
\hline & Bumbo & 18 & 45,72 & 18 & 45,72 \\
\hline \multirow{3}{*}{ 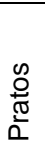 } & Chimbal & 14 & 35,56 & - & - \\
\hline & Ataque & 16 & 40,64 & - & - \\
\hline & Condução & 20 & 50,80 & - & - \\
\hline
\end{tabular}




\section{Discussão dos resultados}

Nos espectrogramas, o eixo vertical corresponde à frequência em Hertz em escala logarítmica, para melhor visualização. O eixo horizontal é o tempo, em segundos. A escala de cor indica a intensidade da onda sonora em "decibéis a escala completa".(dBFS), com a amplitude RMS de uma onda senoidal correspondendo a 0 dBFS. Na figura 5 vemos o espectrograma das cordas da guitarra sendo acionadas uma a uma, onde é possível ver claramente a série harmônica com uma intensidade relativa bem persente nos primeiros harmônicos. Na figura 6 foi executada uma escala musical, a escala pentablues de Lá menor. A escala é bastante harmônica com a coincidência de frequência de diversos modos de vibração.

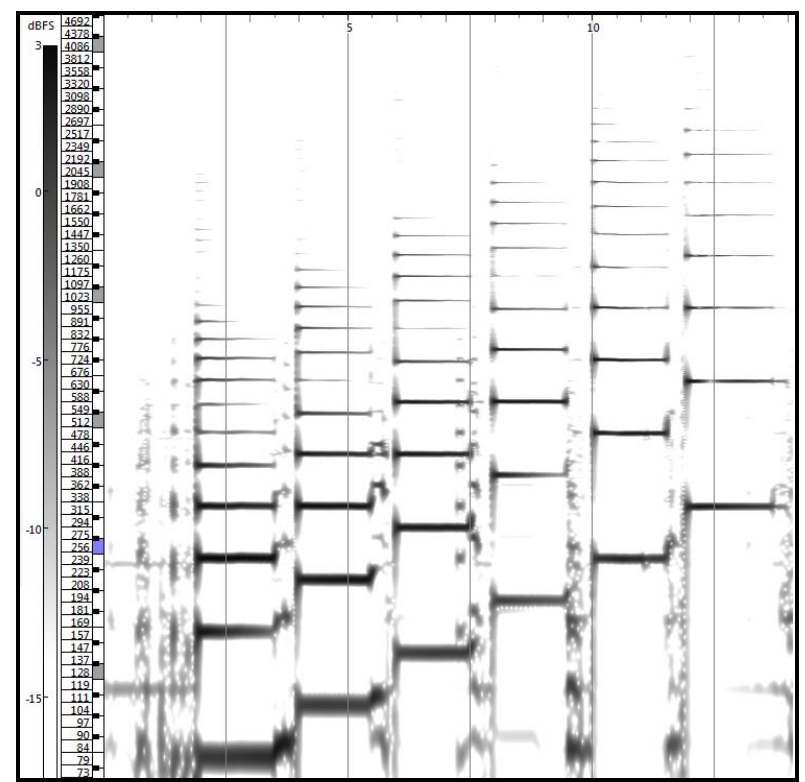

Figura 5: Espectrograma das cordas da guitarra. Da esquerda para a direita temos Mi, Lá, Ré, Sol, Si, Mi. É possível visualizar com clareza a série harmônica em todas as notas.

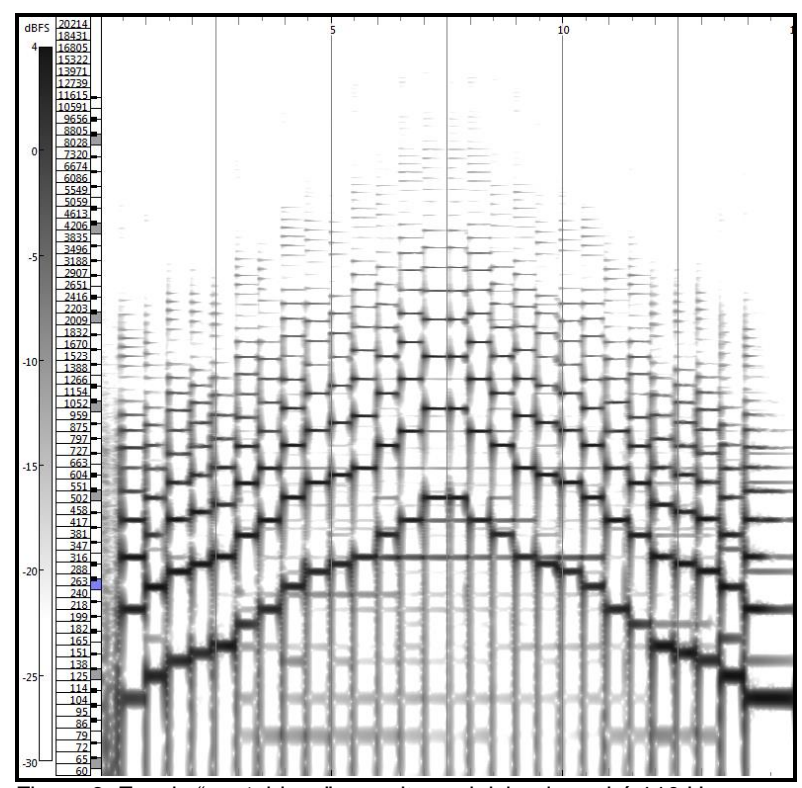

Na figura 7, temos as cordas soltas do baixo. É possível notar a grande extensão espectral desse instrumento partindo da corda Si solta, vibrando a $30,87 \mathrm{~Hz}$ e chega até o Sol $392,00 \mathrm{~Hz}$ na $24^{\text {a }}$ casa da corda Sol (ou o quarto harmônico, na figura 7).

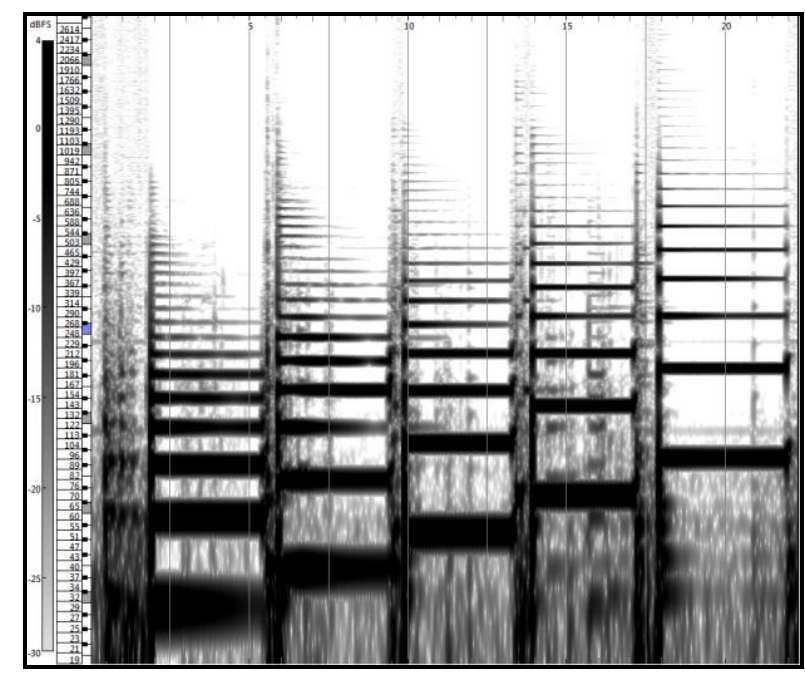

Figura 7: As cordas soltas do contrabaixo: Si, Mi, Lá, Ré, Sol.

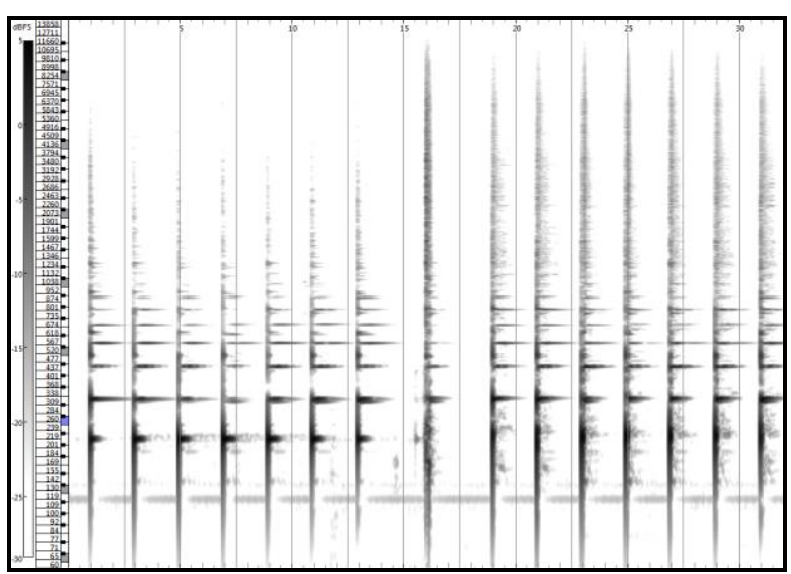

Figura 8: Varredura diametral na caixa sem esteira (esquerda) e com esteira (direita). A região central corresponde ao acionamento do mecanismo da esteira.

A caixa é o tambor mais complexo do conjunto, sendo necessário uma pele em cada extremidade. Na pele inferior, é acoplada uma esteira de molas, que interfere no movimento da pele, que por sua vez é também acoplada à pele superior, devido ao ar no interior do tambor. Na figura 8 podemos notar o efeito da esteira. $\mathrm{Na}$ parte esquerda, o tambor com a esteira desengatada é tocado ao longo do diâmetro. No centro aparece um som parecido com uma batida, devido ao acionamento da esteira e à direita a varredura diametral com a esteira acionada. Com a esteira acionada, o modo fundamental fica impedido de ressoar e muitas frequências aparecem na parte alta do espectro. Curiosamente, o som do acionamento do mecanismo da esteira não é muito diferente do som da caixa tocada com uma baqueta na pele superior. 


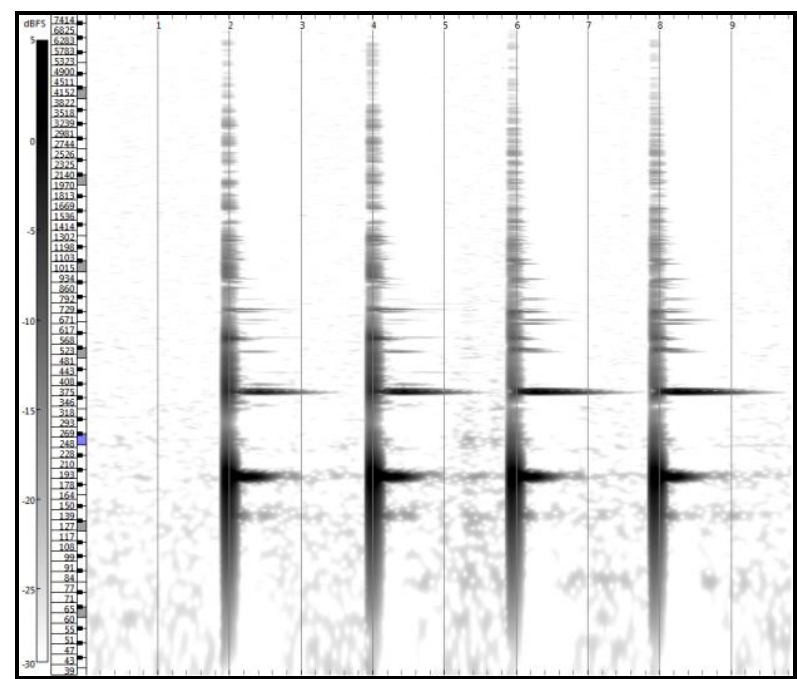

Figura 9: Tom tom de 10" tocado 4 vezes na região central da pele.

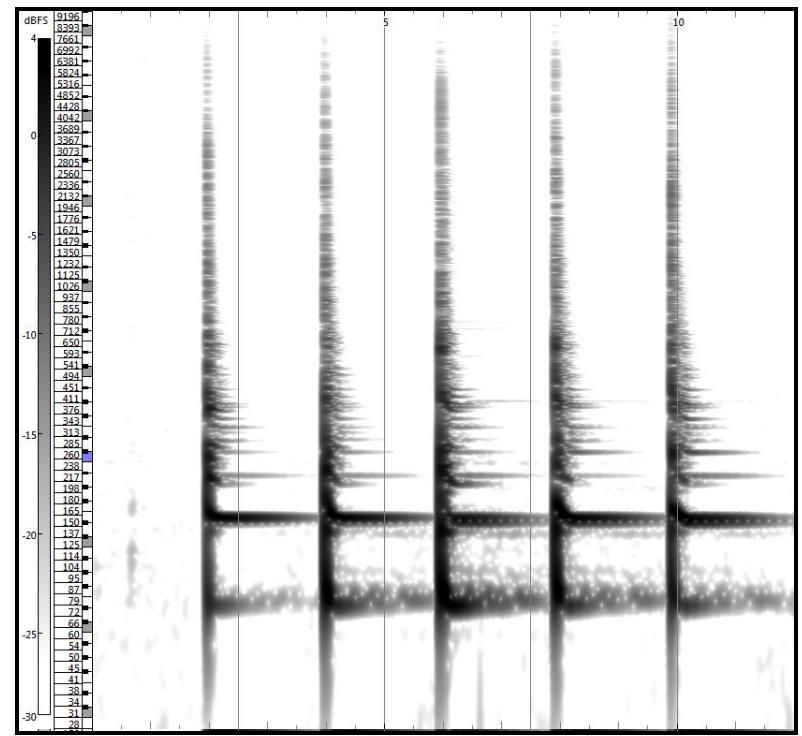

Figura 10: Varredura diametral no surdo de 14".

O tom tom e o surdo, cujos espectrogramas são apresentados nas figuras 9 e 10, respectivamente, apresentam o comportamento sônico mais simples do que o da caixa. Nos dois casos vemos a predominância do primeiro modo superior, mais intenso que o fundamental e de sustentação mais longa. $\mathrm{Na}$ varredura diametral do surdo, é possível notar que a batida no centro do tambor é mais intensa que as demais, mas por outro lado tem sustentação menor.

Para finalizar temos os três principais tipos de pratos usados em geral em uma bateria. O mais frequente nas músicas é o prato de chimbal, que com notas bem curtas, marca os tempos da música. Na figura 11 podemos perceber como a sustentação é suprimida com os dois pratos em contato, mas pode ocorrer quando são separados, através de um mecanismo acionado por pedal. Isso é o que vemos entre as duas últimas batidas na figura 11. Na figura 12, o prato de condução, que possui um transiente bem definido, um modo predominante por alguns segundos, que evolui para modos de frequência baixa ao final da oscilação.

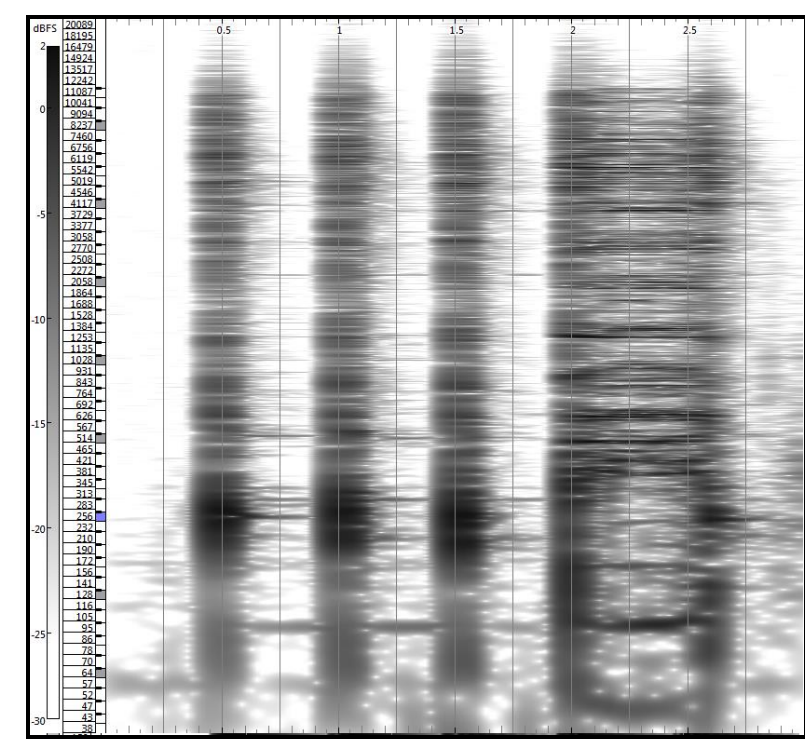

Figura 11: Pratos de chimbal de 14". Entre a quarta e a quinta batidas, o pedal é acionado, causando separação e posterior junção dos pratos.

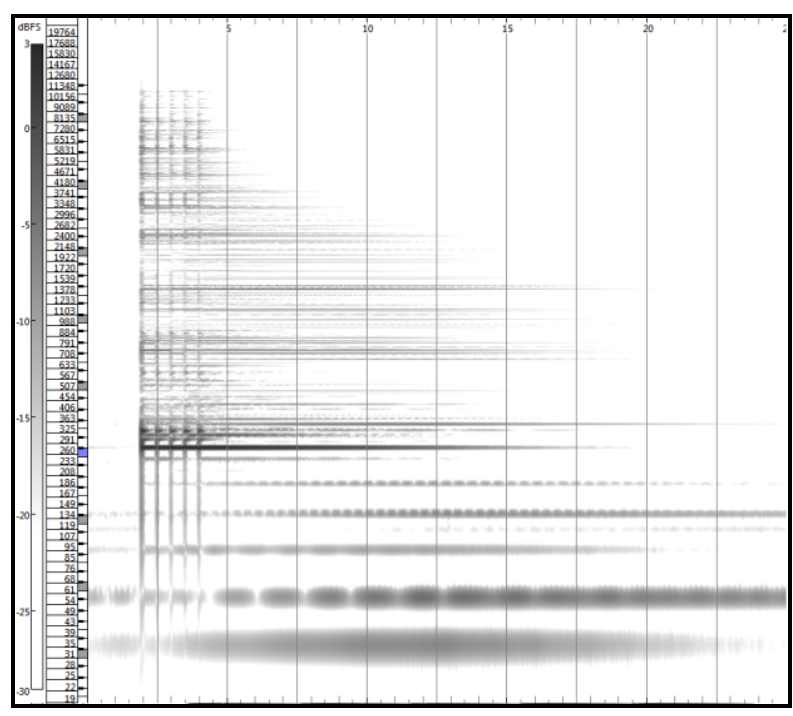

Figura 12: Prato de condução 20" tocado 5 vezes e deixado ressoar.

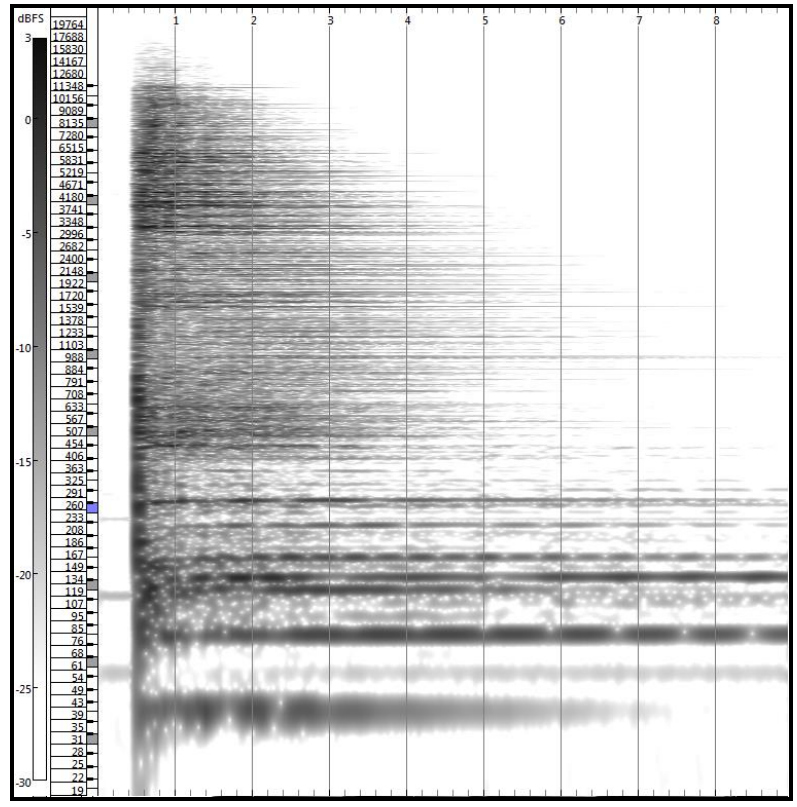

Figura 13: Prato de ataque 16" tocado intensamente uma vez. 
O prato de ataque, cujo espectrograma é apresentado na figura 13 é geralmente utilizado para enfatizar certas passagens da música. A evolução temporal do som desse prato é muito interessante. Após o primeiro transiente, surgem frequências intensas ao longo de todo o espectro, principalmente na região superior, dando a ideia de movimentos não-lineares. Depois de alguns segundos, a oscilação vai convergindo para alguns modos mais estáveis de frequências mais baixas, que vinham se formando e que permanecem até o final do movimento.

\section{Conclusão}

Os espectrogramas do som da guitarra, do baixo e da bateria permitem uma análise profunda das características sônicas desses instrumentos, trazendo informações que ajudam a entender sobre o porquê desses instrumentos serem tão amplamente utilizados. Alguns aspectos de Física Básica e Física Aplicada podem ser discutidos com base nesse tipo de análise, como os modos normais de vibração de cordas, membranas e placas. Concluímos que o trabalho contribui para o debate entra a Física, a Matemática e a Música, bem como para o Ensino de Física, Ensino de Música e popularização da ciência e tecnologia.

\section{Referências}

[1] BELZ, C. The Story of Rock, Oxford: 1972

[2] HALL, M. K. The Emergence of Rock And Roll: Music and the Rise of American Youth Culture. New York: Routledge: 2014.

[3] NIKHITH, T. An Analysis of the influence of Rock music on Pop music. Ashvamegh v. 3, 242017.

Disponível em: https://ashvamegh.net/an-analysis-onthe-influence-of-the-rock-music-on-pop-music/. Acesso em: 23 ou. 2020.

[4] WALD, E. How The Beatles destroyed rock and roll, Oxford: 2009.

[5] PURCELL, E. M. Eletricidade e Magnetismo. Curso de Física de Berkeley, v. 2. São Paulo: Blucher: 1973.
[6] WOODS, C. A. Development arrested: The Blues and Plantation Power in the Mississippi Delta. Verso: 2017.

[7] OLIVER, P. The Story of the Blues, Northeastern: 1998.

[8] SPRINGER, R. (editor). Nobody knows where the blues come from: lyrics and history, Jackson: Mississipi: 2006.

[9] WALD, E. The Blues: A Very Short Introduction, Oxford: 2010

[10] Charting The Blues - The Donegan Phenomenon, 2017. Disponível em: <http://earlyblues.org/britishblues-articles-and-essays-the-donegan-phenomenon/>. Acesso em: 23 out. 2020.

[11] SCHULLER, G. Early Jazz: Its Roots and Musical Development. New York: Oxford: 1968.

[12] SCHULLER, G. The Swing Era: The Development of Jazz, 1930-1945. New York: Oxford: 1989.

[13] WEIR, W. How the Marshall Amp Changed Rockand the Meaning of 'Loud', 2012. Disponível em: $<$ https://www.theatlantic.com/entertainment/archive/201 2/04/how-the-marshall-amp-changed-rock-and-themeaning-of-loud/255705/>. Acesso em: 23 out. 2020.

[14] THIDELL, A. Device for string instruments. US Patent 7,728,210 B2, 01 jun. 2010.

[15] CATELLI, F.; MUSSATO, G. A. Tensão, calibre e frequência das cordas de instrumentos, Rev. Bras. Ensino Fis., v. 36, n. 1, p. 1306, 2014.

[16] NUSSENSVEIG, H. M. Curso de Física Básica Vol. 2: Fluidos, Oscilações e Ondas, Calor. 5a ed. Blucher: 2014.

[17] WORLAND, R. Normal modes of a musical drumhead under non-uniform tension J. Acoust. Soc. Am. 127, 525-533 2010. 